\title{
New Russian funding cuts spark protests from researchers
}

[MOsCow] The Russian cabinet is proposing to cut science funding this year by 26.5 per cent compared with the figures approved by the State Duma - the lower house of the Russian parliament - in January.

The planned reduction - from Rubl 11.2 billion ( $\$ 1.8$ billion) to Rubl 8.2 billion which forms part of a broad programme of public economies, has already led to strong protests from Russian scientists. They picketed the finance ministry in Moscow last week, and plan to block roads into the nation's capital next week.

The protest is being organized by trade unions representing researchers, who have jointly formed the Russian co-ordinating committee of the scientific collectives (RCC).

RCC representatives have met with first deputy minister Valery Kostyuk, who is acting minister of science and technologies during the absence, due to illness, of the recently appointed minister Vladimir Bulgak. Kostyuk promised that the cabinet would start negotiations with RCC after 10 June.

This is the date on which Bulgak is scheduled to lead a governmental commission made up of representatives of his ministry, as well as the ministries of finances, economics and state property. But in a statement, RCC says its meeting with Kostyuk failed to reach agreement on a single issue of importance.

"This further reduction of state financing suggests that there will be a mass liquidation of scientific collectives, with a lot of people engaged in science losing their jobs, and eliminating any prospect of scientists' receiving the higher wages promised to them earlier," says RCC chairman Valery Sobolev.

His deputy, Aleksey Zharov, is even more outspoken: "This sequestrating of the budget means the final and irrevocable destruction of Russian science."

But the cabinet's decision, which led to the the RCC protest, is only the tip of the iceberg. Earlier last month, the government issued a decree indicating that the budget for science will experience even heavier cuts over the next few years.

In 2001, for example, under the government's austerity plans, spending on science will be 0.23 per cent of gross national product, compared with 0.33 in 1997 , falling from 2.1 to 1.8 per cent of public expenditure.

The Ministry of Finances has already written to all research institutes and laboratories emphasizing that strict economies are to be imposed. From next year, state spending on scientific research will be cut by Rubl 1.5 billion each year until 2001 .

Among those likely to suffer are the Russ- ian Foundation for Fundamental Research and the Russian humanitarian scientific foundations, both of which will see their current budgets cut by half.

Furthermore, research institutes will be required to give priority to paying their electricity bills and other communal costs, leaving staff salaries to be paid out of what money —if any — remains.

The budget reduction affects all of the research programme except space research for which, it was reported, the cabinet has managed to find an extra Rubl 1.5 billion.
The government's moves have come in the wake of various proposals it has received that there should be a substantial pruning of research institutes and laboratories, to ensure that only the most competitive survive.

So far, however, efforts to move in this direction have been strongly resisted by the Russian Academy of Sciences. "It is easy to destroy something, but very difficult to build," says Andrey Gonchar, RAS vice-president. "What will be the long-term value of closing institutes and laboratories, even if they are currently ineffective?"

CarlLevitin

\section{Galileo's manuscripts go on the Internet}

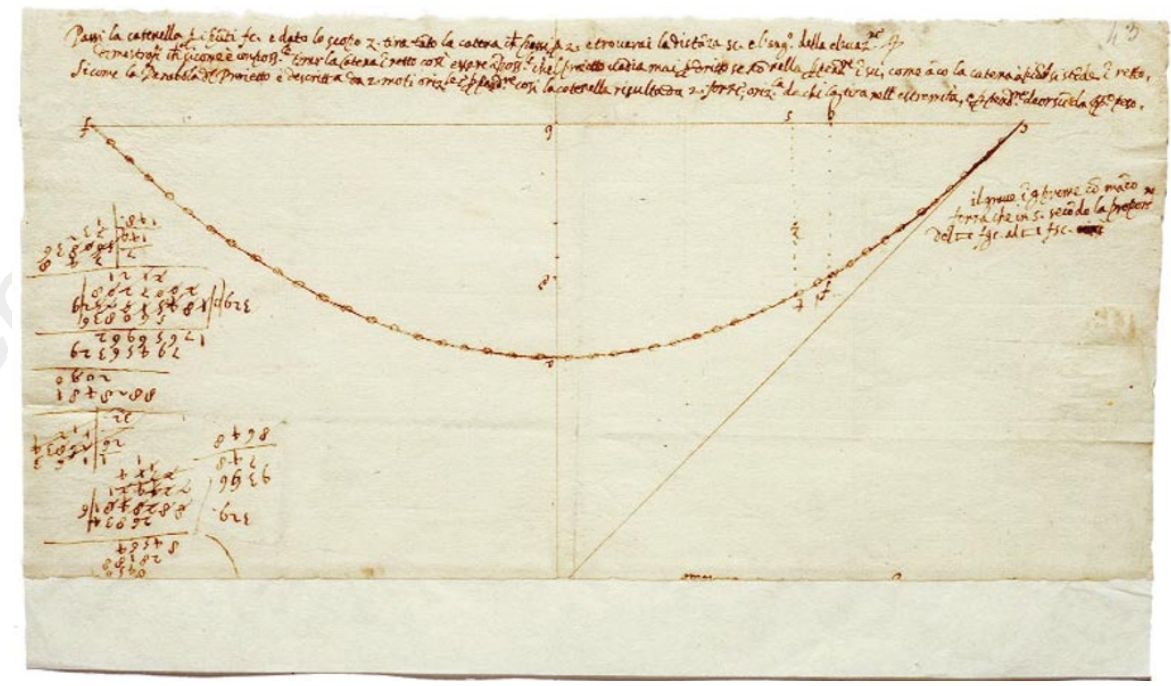

Web page: many of Galileo's manuscripts are now on the Internet, including this one showing an experimental protocol for checking his theory of projectile motion.

[MUNICH] Galileo Galilei's personal manuscripts, in which he wrote down the ideas, calculations and drawings that led to his theory of mechanics, can now be viewed on the Internet. It is believed to be the first historical scientific document of such significance to be made available in this way.

The 300-odd Internet folios are highresolution photographs of Galileo's looseleaf notes - in effect, his laboratory notebooks - from the late 1580s, when he was a young professor at the University of Pisa and still a follower of Aristotle, to 1638, when he published his Discorsi on mechanics. This publication marked a turning point in the development of scientific reasoning and opened the door to modern mechanics.

The Internet publication is a combined project by the Italian National Library of Florence, where most of Galileo's original texts are held, the Institute and Museum for the History of Science in Florence, and the Max Planck Institute for the History of Science in Berlin. All of the Latin and Italian text in the manuscripts has been transcribed and is provided in Italian and English.

The text of the Discorsi is also on the web site and there are hypertext links between the notes and relevant pages in the Discorsi. The website will be modified in response to input from Galileo scholars.

"The Internet is changing the relationship between scholars, libraries and publishers", says Jürgen Renn, director of the Berlin Max Planck Institute. Web access means scholars no longer need to travel to the National Library in Florence to access Galileo's work. Renn says plans to include the collected works of Albert Einstein were abandoned because of copyright problems.

The texts are available on http://uww.mpiwg-berlin.mpg.de or http://unw.imss.fi.it

Alison Abbott 